\title{
CORPO DE LETRAS: ENSINAR OU ENCENAR LITERATURA?
}

\section{LETTERS OF BODY: TEACH OR STAGE LITERATURE?}

\author{
Claudicélio Rodrigues da Silva ${ }^{1}$
}

\begin{abstract}
Resumo: Num momento em que os ministérios da Cultura e da Educação têm incentivado as universidades e institutos federais de educação a gestar e gerir projetos de fomento à cultura em seus espaços, visando enriquecer a vida cultural dos seus estudantes, o presente artigo tem por finalidade o relato de experiências nas aulas de literatura brasileira e estágio do curso de Letras da Universidade Federal do Ceará nas quais a forma de avaliação levou em consideração a leitura do texto literário para se elaborar outros textos e materiais estéticos, visando o contato do futuro professor de educação básica com uma didática que vá ao encontro do que as diretrizes curriculares propõem: um ensino interdisciplinar e sensível ao estético.
\end{abstract}

Palavras-chave: Literatura, Ensino, Currículo, Arte-Educação

Abstract: This paper aims at reporting experiences in literature's brazilian classes and internship of the Letters course of the Federal University of Ceará, in which form of assessment took into account the literary text's perusal to elaborate other texts and esthetic materials, intending the contact of future teachers of basic education with a didacticism that meets the curriculum guidelines that propose: an interdisciplinary teaching and sensible to the esthetic.

Keywords: Literature; Education; Curriculum; Art-Education.

\section{Introdução}

Aprendi com Rômulo Quiroga (um pintor boliviano)

A expressão reta não sonha.

Não use traço acostumado.

A força de um artista vem das suas derrotas.

(Manoel de Barros, “As lições R.Q”)

O curso de Letras da UFC (Universidade Federal do Ceará) e suas respectivas licenciaturas constitui-se de uma dupla função: formar os futuros professores da educação básica e preparar pesquisadores que atuarão numa pós-graduação produzindo reflexões sobre a língua materna, língua estrangeira e literatura. Independente de uma dessas funções, não se pode pensar a língua e a literatura - seu estudo teórico-crítico e as metodologias para o seu ensino - desvinculadas das outras linguagens. Não apenas as novas diretrizes curriculares para educação básica têm solicitado o ensino das variedades da língua materna concomitante ao uso de outras linguagens (TICs, cinema e artes visuais), quanto a própria proposta do programa de pós-graduação em literatura comparada da UFC pressupõe o contato da literatura com outros campos de saber, sobretudo com as outras artes.

No caso específico do novo ensino médio, a área de "Linguagens, códigos e suas tecnologias", desde a formulação e apresentação dos PCNs no final da década de 1990, orientava a escola para o ensino encerrado nas certezas das disciplinas e se lançasse rumo à experimentação de práticas pedagógicas que aliassem o saber fazer ao saber ser, ou seja, o domínio da utilidade e da fruição. Enquanto a palavra utilidade é benvinda nos objetivos do ensino marcadamente orientado à formação para o mercado de trabalho, a palavra fruição

\footnotetext{
${ }^{1}$ Professor adjunto de Literatura Brasileira e de estágio em Ensino de Literaturas de Língua Portuguesa na Universidade Federal do Ceará. E-mail: claudicelio@gmail.com.
} 
parece ser um tormento na reformulação do ensino, porque é cumulada de uma incompletude, circunscrevendo o sentido ao gozo, à ruptura de decisões e com preferência à cisão. Roland Barthes assinala esse caráter fugidio ao descrever um texto de fruição como "aquele que põe em estado de perda, aquele que desconforta [...], faz vacilar as bases históricas, culturais, psicológicas, do leitor, a consistência de seus gostos, de seus valores e de suas lembranças, faz entrar em crise sua relação com a linguagem" (1987, p. 21-22).

A exemplo das artes de vanguarda, que, no início do século $\mathrm{XX}$, não apenas alteraram a noção do belo na arte e de sua função social, numa mistura de linguagens, o mundo contemporâneo sugere ao artista e ao professor a ressignificação da arte, para que se repense seu papel diante da enxurrada de aplicativos e informações que abundam nas mídias. É necessário tirar daí algum saber, mas tal saber não pode ser aleatório. Desde o primeiro período do curso de graduação, o aluno de Letras se depara com um impasse: pensar a literatura e a língua em sua diversidade não requer que haja um exercício de criticidade e criatividade ao lado do ensino? Como trazer para o corpo das Letras o fomento à produção cultural, favorecendo que se pense a produção da arte ao mesmo tempo em que se experimente a criação estética?

As diretrizes e os parâmetros curriculares, por sua vez, apostam numa educação que valorize o espaço não só da manutenção e ampliação de um saber, mas, sobretudo, no fomento à produção de novos saberes que culminem numa formação do sujeito voltada para a percepção do mundo pela pluralidade do olhar, entre os quais se insere a arte, suas formas contemporâneas e seus usos. Um currículo é, desse modo, uma construção cultural cujo campo de produção pressupõe escolha e produção de saberes, "campo conflituoso de produção de cultura, de embate entre pessoas concretas, concepções de conhecimento e aprendizagem, formas de imaginar e perceber o mundo" (DCN, 2013, p. 24) ${ }^{2}$.

Visando à formação de um profissional sensível a isso, ou seja, que possa situar os componentes curriculares em espaços de produção de saber contextualizado e significativo, é que ações como as que serão desenvolvidas no projeto precisam ser implementadas no Curso de Letras. Esse futuro professor atuará numa escola cujas formas de ensino sugerem um redesenho das práticas, sobretudo no âmbito da pedagogia de projetos, aulas inseridas em macrocampos de conhecimentos, além de espaços de produção de saberes transversais. $\mathrm{O}$ problema é que desde a nova LDB/96, enquanto interdisciplinaridade e transdisciplinaridade são recorrências nos diversos documentos e diretrizes, nas escolas e nos cursos de formação de professores elas são apenas discurso. Currículos são reformulados, projetos políticos pedagógicos reestruturados, regimentos e mais regimentos se elaboram, e a configuração do ensino continua praticamente igual: cada professor ministra um rol extenso de conteúdos considerados importantíssimos para a formação do aluno e se nega a sair da sua zona de conforto para refletir que conteúdo é algo maleável, aberto, sempre em vias de mudança. Alguns professores alegam que os estudos inter e transdisciplinares enfraquecem o ensino enquanto a disciplina se dissolve. Tal concepção desconhece justamente o objetivo de uma abordagem pela disciplina, mas, sobretudo, além dela:

A transdisciplinaridade refere-se ao conhecimento próprio da disciplina, mas está para além dela. $\mathrm{O}$ conhecimento situa-se na disciplina, nas diferentes

\footnotetext{
${ }^{2}$ O campo é tão conflituoso que, analisando os PCNEM (1999), os PCNEM+ (2002), as matrizes curriculares do ENEM e as Diretrizes Curriculares Nacionais para a Educação Básica (2013), pouco se discute o ensino da literatura, suas peculiaridades ou os métodos para a formação do leitor do texto literário. O que se coloca claramente são bibliografias geralmente concernentes aos estudos linguísticos (uma forte adesão aos gêneros discursivos), como se tais concepções servissem de base para a leitura e compreensão de qualquer texto.
} 


\section{Notandum 42 set-dez 2016 - CEMOrOC - Feusp / IJI-Univ. do Porto DOI: http://dx.doi.org/10.4025/notandum.42.2}

disciplinas e além delas, tanto no espaço quanto no tempo. Busca a unidade do conhecimento na relação entre a parte e o todo, entre o todo e a parte. Adota atitude de abertura sobre as culturas do presente e do passado, uma assimilação da cultura e da arte. O desenvolvimento da capacidade de articular diferentes referências de dimensões da pessoa humana, de seus direitos, e do mundo é fundamento básico da transdisciplinaridade. (DCN, 2013, p. 28)

As diretrizes curriculares nacionais para a educação básica são claras quando sugerem que as diferentes "dimensões da pessoa humana, de seus direitos, e do mundo é fundamento básico da transdiciplinaridade" (DCN, 2013, p. 28). Do mesmo modo, os $\mathrm{PCN}+{ }^{3}$, documento de orientações educacionais complementares aos parâmetros, indicam que

Não se cogita descaracterizar as disciplinas, confundindo-as todas em práticas comuns ou indistintas. O que interessa é promover uma ação concentrada do conjunto e também de cada uma das disciplinas, a serviço do desenvolvimento de competências gerais, que dependem do conhecimento disciplinar. (2002, p. 17).

É nesse sentido que cabe à escola partir de uma referência de conteúdo que integrem necessariamente uma formação holística, dando ao aluno a possibilidade para se constituir como sujeito não por acúmulo do que se entende fundamental para sua formação, senão por relações afetivas que possibilitem experienciar o sensível. Não é possível ainda que se confunda formação com acúmulo. O que nos constitui como sujeitos é tanto o que adquirimos ao longo da vida quanto o que nos falta. A insuficiência também possibilita um modus operandi e um modus vivendi.

Um dos maiores desafios de um curso de licenciatura é, sem dúvida, a urgência de uma formação que repense uma nova educação básica, ou seja, que forme um professor para modificar o ensino e não para ser mero repetidor de padrões e de métodos anacrônicos. Esse impasse é visível na universidade, quando o aluno se depara com uma metodologia que não leva em conta, por exemplo, um ensino linear, padronizado, referendado por um historicismo ${ }^{4}$. Passam a questionar a validade dessa metodologia, sua complexidade, sua natureza insurgente, sentem-se confusos diante de um ensino que não favorece mais os esquemas, mas, ao contrário, mostra que a literatura não tem um caráter autônomo, pois outros saberes podem e devem ser acessados para se compreender a natureza do texto literário. O contexto, nesse caso, passa a ser não mais somente a época em que obra foi feita ou as disposições do autor, mas os temas que a obra suscita e que, necessariamente, levam-nos aos estudos sociais, à psicanálise, à filosofia, à religião, às outras linguagens artísticas etc.

Se desejarmos refletir sobre um ensino de língua e literatura que parta do texto (literário ou não) para formar sujeitos/protagonistas, é preciso promover ainda na universidade esses espaços de integração das diversas linguagens. A ilusão de que o ensino só tem êxito se for pautado em conteúdos conceituais unidimensionais acaba por alimentar a manutenção de práticas que desconsideram os elementos atitudinais e procedimentais como conteúdos tão

\footnotetext{
${ }^{3}$ MINISTÉRIO DA EDUCAÇÃO. Caderno de Linguagens, códigos e suas tecnologias dos PCN+. Brasília, 2002, p. 17.

${ }^{4}$ É preciso não confundir historicismo com historicidade. Enquanto esta situa um sujeito e um objeto num contexto, tratando-os também além do tempo, aquele, ao situar sujeito e obra num tempo, demarca-os, limita-os e tenta entende-los em seu todo, como se fosse possível encerrá-los como construções esquemáticas.
} 


\title{
Notandum 42 set-dez 2016 - CEMOrOC - Feusp / IJI-Univ. do Porto DOI: http://dx.doi.org/10.4025/notandum.42.2
}

importantes quanto os conceituais. Denunciando essa concepção, o professor Moaci Alves Carneiro afirma:

\begin{abstract}
Há quem pense que o currículo formal é suficiente: contém o conhecimento sistematizado por área, os conceitos, as definições e as informações científicas e culturais necessárias à adequada formação da inteligência. As emoções... bem, estas ficam de fora porque não pertencem a uma escola comprometida com uma educação intelectual! (2012, p. 167).
\end{abstract}

Muito se tem discutido sobre como estudar literatura. Mais amplamente, já se tornou recorrente também o questionamento sobre por que estudar literatura. Em Quem ama literatura não estuda literatura: ensaios indisciplinados (2008) Joel Rufino dos Santos provoca já no título uma instabilidade em quem é professor de literatura. O título parecer desautorizar o ensino da literatura, derrubá-lo de um certo trono de poder em que se senta o professor de literatura do curso de Letras. Mas é preciso não se fixar nessa redução de sentido apenas, já que o próprio autor foi professor de literatura brasileira em curso superior durante anos ${ }^{5}$. Será que os programas de ensino da literatura têm contribuído para formar leitores na manutenção de uma metodologia cujo foco é o estruturalismo? Ainda, é possível dizer que o estudo das obras literárias canônicas em um esquema historiográfico favorece as obras? Há problematização da função social, política, ética e estética do texto literário? O ensino empreende a reflexão de por que certos autores figuram constantemente em qualquer lista de ensino enquanto outros, ainda que bastante lidos, mantêm-se à margem dos currículos?

É possível ensinar literatura sem refletir seu aspecto sensível, que suscita no leitor uma contemplação e avaliação de mundo? É possível pensar o ensino de literatura partindo única e exclusivamente de uma história da literatura sem levar em consideração que a obra é fruto de uma ética e estética? Todas as concepções e teorias (bem como a crítica e a historiografia) têm sua relevância, mas não podem prescindir do caráter básico do texto literário: revelar um mundo, suscitar no leitor uma reflexão sobre o ser no mundo. $O$ ensino de literatura pressupõe não somente a constituição e estudo de uma forma, mas também o reconhecimento de uma força, daí que sendo arte, ela também opera uma ética ou, como aponta Vincent Jouve: "Se a arte não existe mais para os teóricos, ela ainda existe para a maioria dos indivíduos e, sobretudo, para uma série de instituições (ensino, imprensa, mídias) que pesam fortemente sobre nossa existência cotidiana" (2012, p. 10-11). Ora, se os mecanismos sociais exigem de nós um reconhecimento do mundo exterior para que possamos atuar nele de modo crítico, é óbvio que nossa interioridade, ao reclamar um olhar atento, acaba por contribuir significativamente no modo como atuamos.

Assim, para se redesenhar o currículo de um curso como o de Letras, plural em sua essência, é preciso partir de duas constatações:

a) Sua natureza formativa para o mercado de trabalho. O curso tem um objetivo geral que não se deve negligenciar: sendo uma licenciatura, atua eminentemente na formação de professores que deverão atuar no ensino fundamental e médio, etapas da Educação Básica. Desse modo, é imprescindível que os programas dos diversos componentes curriculares dialoguem com as diretrizes curriculares de atuação do futuro professor. É no mínimo questionável um curso que deve formar professores cuja unidade de teoria e prática de ensino

\footnotetext{
5 Além de ser escritor de crônicas e obras infanto-juvenis, Joel Rufino dos Santos ministrou aulas no curso de Letras da UFRJ.
} 
exista no projeto político pedagógico e não se constitua objetivamente como um espaço de questionamento do ensino e a necessidade de redefinir rumos. Nesse caso, é urgente uma formação por áreas de saber, onde as disciplinas se reúnam em núcleos comuns num primeiro momento para depois ultrapassá-los, observando o caráter indisciplinado dos saberes. Ou seja, nem todo conteúdo aceita uma gaveta porque tem um caráter de transitividade. No caso da área de Linguagens, Códigos e suas Tecnologias, é preciso que o curso de Letras se volte para a constituição das competências e habilidades que fundamentam o novo ensino médio (bem como o ENEM) e se questione sua constituição e a inexpressiva presença do texto literário aí, o que pode induzir o professor a pensar que a literatura foi preterida na relação com as diversas linguagens e códigos.

b) Seu aspecto de formação de pesquisadores. Voltando-se ao curso e à universidade, amplia a permanência dos alunos além de uma graduação, possibilitando que se especializem strito sensu em um determinado programa. Serão pesquisadores em suas áreas e atuarão para aprofundamento de questões referentes à língua e a literatura no que ambas têm de marcas de um tempo e de um lugar.

Em ambos os casos, deve-se entender que há sempre uma conexão a ser ativada para trás (à educação básica) e à frente (à permanência do sujeito na instituição). Mas é pensando especificamente na formação para atuação na educação básica que esse artigo expõe experiências desenvolvidas por professores e alunos do curso de Letras da UFC no intuito de integrar um conteúdo conceitual sobre literatura com uma outra arte. Essa abordagem, no entanto, não tem qualquer pretensão de encerrar a forma de se trabalhar um conteúdo, ou de se constituir o curso. Estamos no campo das experiências que nos coloca necessariamente no âmbito das possibilidades e não das certezas.

\section{Quando a literatura se encena no corpo do aluno}

Usando como base as experiências pessoais enquanto professor de língua portuguesa na educação básica, ao ingressar na docência do ensino superior planejei um programa para o ensino de literatura brasileira cuja metodologia integrasse uma constituição elementar de textos sobre ensino e literatura, as obras literárias e dinâmicas que tornassem possível o caráter interdisciplinar de formação do professor para atuar na área de Linguagens, códigos e suas tecnologias.

Assim, nas disciplinas de estágio em ensino de literaturas de língua portuguesa, aos textos que norteavam o ensino da literatura foram elencadas oficinas de produção de escrita criativa e de arte-educação. Nenhuma dessas oficinas, entretanto, ocorria sem que o texto literário fosse o ponto de partida e de chegada. Nesse caso, uma unidade didática partiu da temática das "escritas de si" com a leitura de autorretratos de poetas como Adélia Prado, Manoel de Barros, Graciliano Ramos e Mário Quintana. À leitura e análise da forma e da autorreflexão dos poemas seguiu-se também uma atividade na qual os alunos foram convidados a escolher um entre as estruturas dos textos lidos para compor seu autorretrato. Em outro momento, os alunos deveriam transpor para um cartão sanfonado o seu texto, como uma linha do tempo ilustrada. Numa culminância, é feita uma exposição dos trabalhos e cada aluno é convidado a partilhar sua experiência com os demais. 


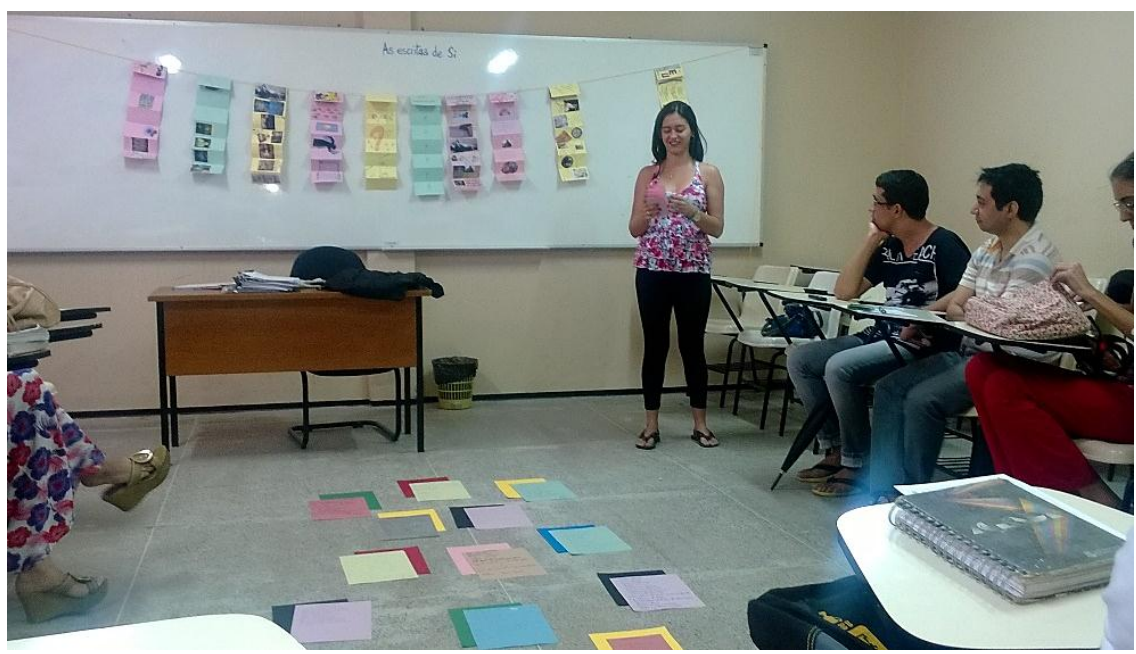

Figura 1. Apresentação de autorretrato poético na aula de Estágio em Ensino de Literaturas.

Outra oficina, ministrada para alunos do Estágio I em Literatura, em 2014.2, trabalhouse a forma do gênero microconto e temática contos e romances do cânone ocidental. Apresentando duas obras elaboradas a partir de microcontos ${ }^{6}$, analisou-se, entre outras coisas, o poder de síntese do texto minimalista, sua poeticidade, sua narrativa que mais sugere do que releva e deixa lacunas que devem ser preenchidas pelo leitor. Em seguida, os alunos foram convidados a produzir textos apropriando-se das narrativas do cânone ocidental A atividade culminou na produção de um livreto cujas etapas - escrita, produção de capa e diagramação foram feitas coletivamente ao longo do semestre. Exemplos dos textos produzidos a seguir demonstram a criatividade na desconstrução das obras através de uma paródia cuja finalidade se voltou à crítica dos enredos:

JECA

Acocorou-se atrás do poste. Checou os dois lados do beco mal iluminado. No apê de 20 andares vizinho, o olfato de Lobato sentiu que estivera ali um Jeca. (Maria Eugênia)

\section{CARTAS PARA BASÍLIO}

Caro Basílio, você não passou de uma aventura. Fique em Paris com a sua elegância superficial e não penses que morrerei por você. Meu Paraíso está mesmo ao lado de Jorge. Espero ver-te nunca mais. Att, Luiza. (Fernangela Diniz)

\section{PARA SEMPRE RETICENCIAS}

No quarto mais alto de uma torre, uma única vela feria o escuro. Diante de um espelho velho, grande e sujo, uma moça desnuda mirava-se. Seu olhar seguia as mãos que acariciavam as linhas de seu corpo: nas curvas alvas e suaves de uma mulher, descobrira o homem de sua vida. Naquela noite sem príncipe, amava a si mesma. (Vilk Pereira de Almeida)

Ao elaborar um texto pautando-se não mais apenas no domínio crítico sobre literatura, mas utilizando as próprias ferramentas de composição poética, mostrou-se, no mínimo, eficaz

\footnotetext{
${ }^{6}$ As obras são Estórias Mínimas, de José Rezende Jr e Os Cem Menores Contos Brasileiros do Século, organizado por Marcelino Freire.
} 
no sentido de promover uma desestabilização naquilo que o aluno entende por literatura. Quando nos colocamos no lugar do autor, percebemos como o fazer literário, ainda que pareça, não é simples desejo de escrita. Entram aí outros recursos, mas sobretudo a leitura atenta do repertório literário por meio da qual o aluno-leitor pode exercitar aquilo que antes foi objeto apenas de uma teoria e crítica. O objetivo não é formar escritores, mas justamente fazer o aluno entender que atividades como essa possibilitam outros acessos ao texto literário, porque são também formas de ler.

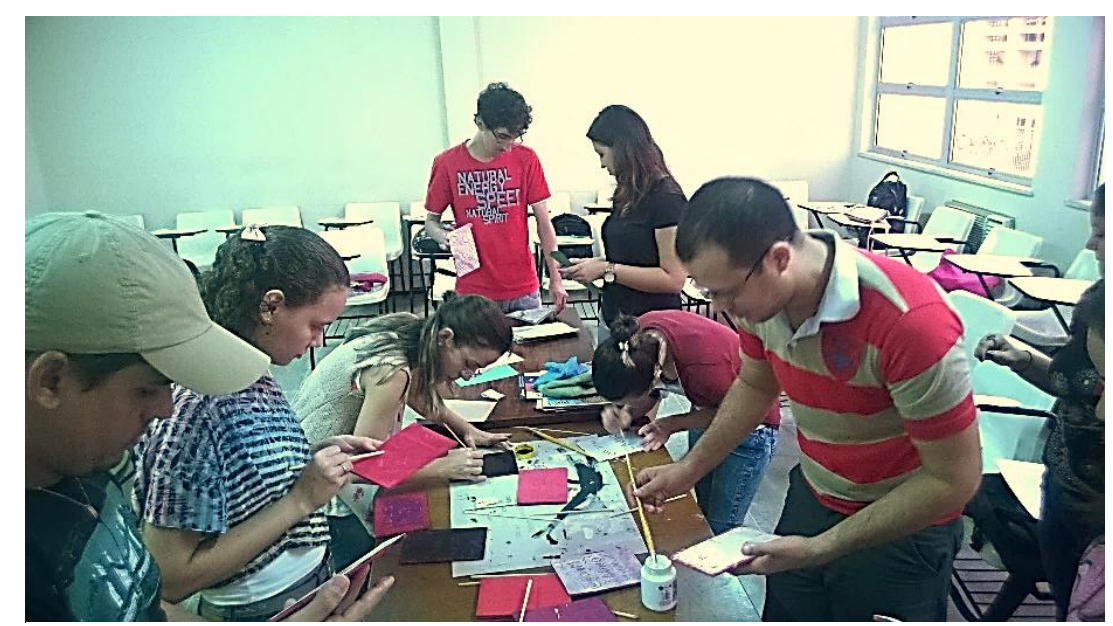

Figura 2. Oficina de produção de capa para o livro com microcontos.

Já na disciplina de literatura brasileira III (ministrada em 2014.2 e 2015.1), destaco quatro atividades apresentadas como alternativas para a avaliação tradicional. A primeira proposta consistiu na leitura de Os Sertões, de Euclides da Cunha, seguida da transposição do texto em prosa para o verso. Divididos em grupos, os alunos realizaram uma garimpagem de frases da obra, buscando desconstruir e reconstruir a obra, mas no gênero poema, não só se apropriando do refinamento do autor, mas reconhecendo aí uma potência poética. O poema abaixo ilustra a proposta:

\section{Crime e loucura ${ }^{7}$}

Grande povo pelo avesso

Um conjunto estranho

De nacionalidades

Miragens sangrentas

Sem olhar e sem risos

A vertigem

Abramos este livro

De cores

Fechemos este livro

Sem brilhos

\footnotetext{
${ }^{7}$ Ilza de Olivera F. Passos e Milton Bitu Pinheiro, coautores do texto, foram alunos de Literatura Brasileira III no primeiro semestre de 2015.
} 
O que se traçou aí foi uma cartografia poética, a própria instabilidade do texto euclidiano, a sonoridade, a cor, a erudição misturada ao popular, a frase de efeito num parágrafo sumaríssimo e os inúmeros capítulos curtos esquadrinhando e mapeando esses sertões de papel e tinta. Ou seja, é possível ver Euclides no poema, mas é também possível ver os alunos, suas marcas autorais na organização e seleção poética do texto. A coletânea de poemas, intitulada de "Os sertões de cada um" foi transformado num livreto e disponibilizado on line para a turma.

A segunda proposta, partiu da elaboração de produtos estéticos que traduzissem as questões apresentadas nos estudos sobre antropofagia cultural, seguindo como base o manifesto antropófago de Oswald de Andrade. Também divididos em equipes, os alunos tiveram à disposição as seguintes sugestões de produtos: fanzine, uma página do facebook, um vídeocolagem, um áudio-colagem, um caligrama ${ }^{8}$. Cada equipe deveria partir dos textos e reflexões da aula, mas era preciso fazer emergir a antropofagia à superfície do Brasil do tempo presente, confrontando a proposta dos modernos com a situação política atual.

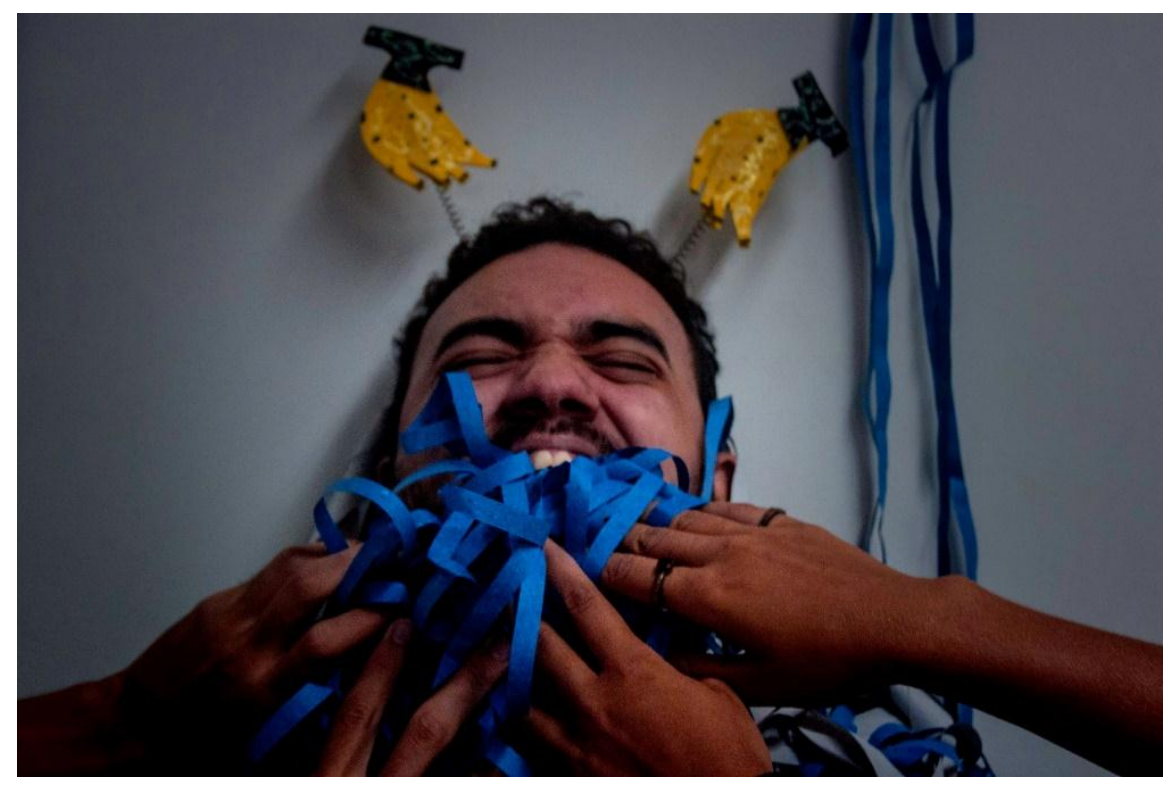

Figura 3. Ensaio fotográfico sobre antropofagia cultural. Equipe composta por Rafael Lima, Beatriz Pessoa, Milton Bitu, Reginaldo Andrade e Leudilânio Alves, fotografia de Ítalo André e edição de imagens de Yan Jamacaru.

A terceira proposta pretendia substituir as análises e apresentações das obras literárias tradicionalmente apresentadas em forma de seminários por outro tipo de apresentação. Apenas uma equipe, entretanto, optou por fazer diferente. Os alunos Lucio Flávio Gondim, Amanda Grazielle Gomes e Paulo Renan, com experiência respetivamente em teatro, música e dança, produziram, montaram e atuaram numa aula-espetáculo numa releitura de Alguma Poesia ${ }^{9}$, de Carlos Drummond de Andrade. Ministrada no palco do teatro universitário em 08 de junho de 2015, a aula-espetáculo mesclava momentos de leituras dos poemas do livro e reflexões sobre o cotidiano dos atores-alunos, numa clara identificação com as questões existenciais suscitadas

\footnotetext{
${ }^{8}$ link para áudio-colagem: https://www.youtube.com/watch?v=1wIAZWwPThg

${ }^{9}$ link para trecho da aula : https://www.youtube.com/watch?v=RRteHULvVmE
} 
nos poemas. As esquetes tomaram como argumento o diálogo entre duas das sete faces do sujeito lírico drummondiano, conforme se pode verificar no trecho a seguir retirado da esquete de abertura:

LÚCIO (centro da sala): Quando eu nasci não havia nenhum anjo torto em Quixeramobim. Conselheiro era morto; Fausto Nilo já tinha composto; Não sobrara nenhum querubim. Talvez por isso tenha a cidade decidido colocar o hospital-maternidade em cima de um morro. Abençoar o sertão era, para cada recém-nascido, mais que uma missão natural, um direito imposto.

RENAN (centro da sala): Eu não gosto de dizer quando eu nasci. Não tenho certeza se o céu entra em festa todo ano porque é nosso aniversário. A gente nasce, os anjos saem, as trombetas soam e... Pronto. Gauche. E todos os dias, os querubins e os arcanjos decidem se fazem som ou silêncio com o que a gente resolveu fazer da nossa vida, que é vida e que é morte... todo dia!

LÚCIO: Talvez por isso eu tenha sido colocado com dois meses num carro em direção à capital. Aprendi a viver entre os que me gritam cotidianamente: "Vai, Flávio... Vai ser Fortaleza na vida!" (risada irônica)

RENAN: Eu gosto daquele verso dele sobre o coração... Ou é sobre o mundo? Ou é uma comparação? O meu peito se transformou numa data comemorativa das datas que não se comemora. Meu nome é Renan, mas eu também não tenho solução.

Lúcio, que enquanto Renan dizia esta última fala, juntava folhas do chão, ao fim da fala, joga as folhas no ar e, com raiva, diz:

LÚCIO: Carlos, você tem ainda tem jeito!!

RENAN (começa a tentar organizar os papeis no chão): Não, a vida parou...

LÚCIO: ... Foi só um automóvel, lá na avenida, que estacionou ao lado do bonde!

RENAN: Não me fale das pernas! Há máquinas terrivelmente complicadas para as necessidades mais simples.

LÚCIO: Exagero, Carlos. Itabira ainda não virou a ilha de Crusoé!

RENAN: Você não sabe como é!

LÚCIO: Eu também já fui brasileiro... Como era mesmo a "Canção do Exílio"?

RENAN: Um poeta anti-federal, tirando ouro do buraco do...

Os dois se reprimem com o olhar.

LÚCIO (bem compassado): Vamos parar por aqui? (Um instante de silêncio) Eu ainda preciso escrever... ${ }^{10}$

\footnotetext{
${ }^{10}$ Esquete de autoria dos alunos Lucio Flávio e Paulo Renan.
} 


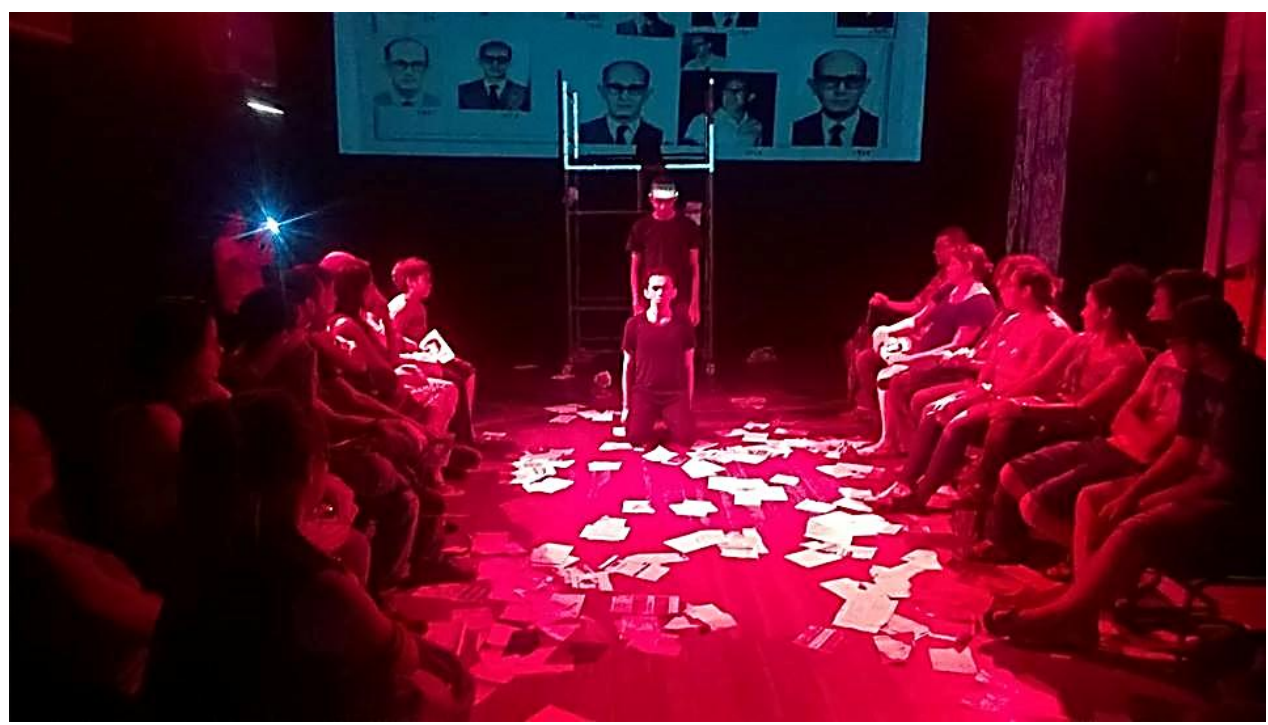

Figura 4. Aula-espetáculo produzida e encenada por alunos.

Todas essas atividades deveriam servir de material de preparação para uma performance que seria produzida e apresentada pelas turmas ao final do semestre como culminância da disciplina. Entretanto, diante da pouca adesão, o convite foi estendido a alunos de outras disciplinas e de outros cursos. Ao longo do semestre, à medida que as obras literárias e seus respectivos textos críticos foram sendo trabalhados em sala, a equipe de elaboração da performance se reunia comigo para estabelecer um programa do que deveria ser a apresentação. Ao final do semestre, tínhamos uma equipe de dez alunos (alguns oriundos de cursos como Matemática, Ciências Sociais e Música, por exemplo) que se organizaram entre atuação e produção do espetáculo. O roteiro de "Where is Iracema?", finalizado após oito versões, o que comprova o caráter movente das discussões em torno dos temas literários a ser encenados, discutia o mito do nacionalismo confrontando dois momentos: o romantismo e o modernismo. A apresentação ocorreu por ocasião do II Encontro Nacional de Estética, Literatura e Filosofia, coordenado pelo Programa de Pós-graduação em Literatura da UFC ${ }^{11}$. O trecho a seguir demonstra como os conteúdos se organizam de modo crítico no espetáculo:

\section{CENA 3: ROMANTISMO versus MODERNISMO}

TELA: As duas versões de Abaporu surgem seguidas da frase "Tupi or not Tupi?" Os performers irão guerrear entre si, formando inicialmente duas gangues que disputarão, num cabo de guerra, ideologias artístico-literárias por meio de frases que representam o Modernismo e o Romantismo.

TEXTO:

Laís:- "Além, muito além daquela serra nasceu Iracema"...

Lucio: - Não senhor: "No fundo do mato virgem, nasceu Macunaíma".

Amanda: - Iracema, a virgem dos lábios de mel...

Karina: - Macunaíma, preto retinto...

Vládia: - Iracema, que tinha o cabelo mais negro que a asa da graúna...

Fábio: - Macunaíma, filho do medo da noite.

Laís: - Iracema corria mais do que Macunaíma, ora!

Lúcio: - Macunaíma corria mais do Iracema, ora!

Amanda: - Iracema era virgem de Tupã!

Karina: - Macunaíma perdeu a virgindade foi cedo, ó!

Vládia: - Iracema é o mesmo que América!

\footnotetext{
${ }^{11}$ link para trecho da apresentação: https://www.youtube.com/watch?v=OCOXv_4X0WU
} 
Fábio:- Oxe, Macunaíma também.

Gleycie: - Iracema morreu de tanto amor...

Karina: - Macunaíma morreu de tanto amar...

Valter: (interrompendo) Chega! Ai! Que preguiça! (acocora-se, enquanto o cabo-de-guerra se desfaz)

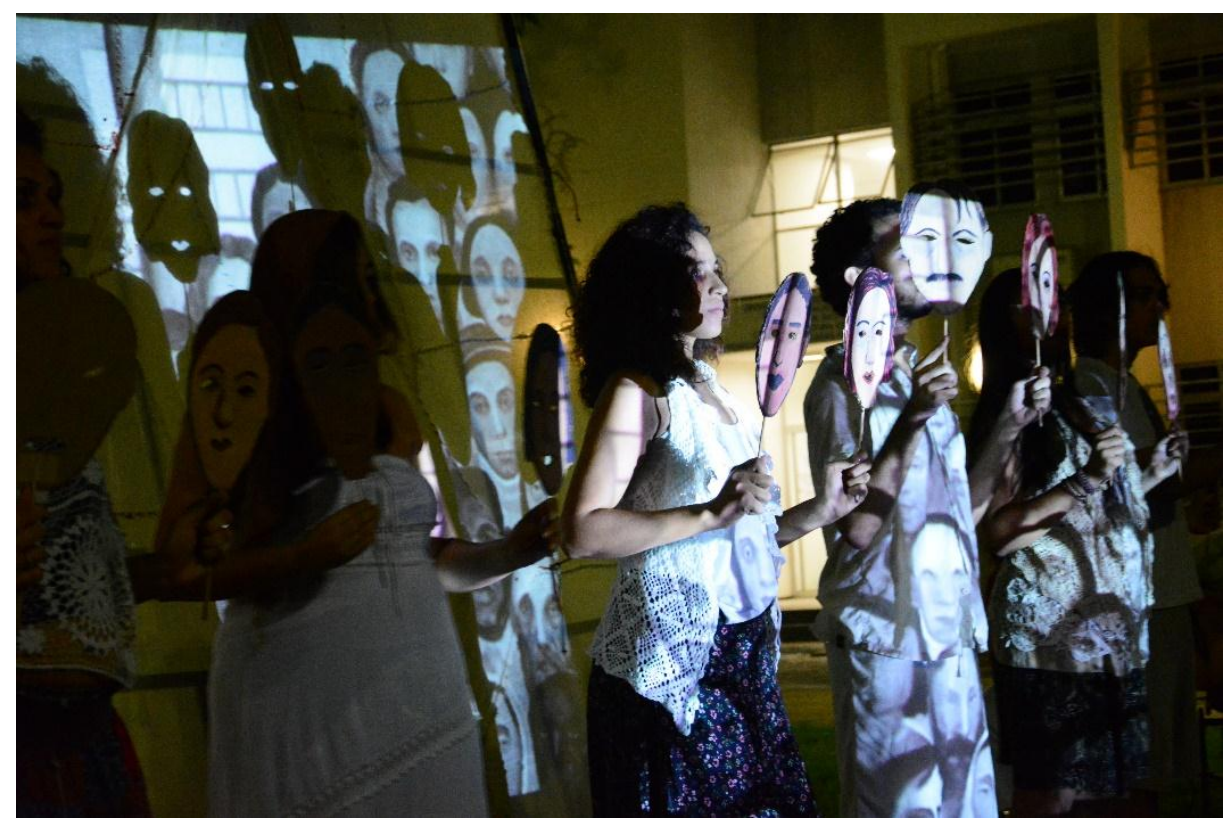

Figura 5. Cena de Where is Iracema?. Alunos interagem com o quadro Operários de Tarsila do Amaral.

\section{AVALIAÇÃO E PERSPECTIVAS}

Nas quatro turmas de brasileira III e nas turmas de Estágio em Literatura em que essas propostas de trabalho foram apresentadas houve resistência ou, no mínimo, um certo desconforto. É preciso ressaltar que, apesar de algumas demonstrações de desagrado, todas concluíram suas atividades e, de certo modo, repensaram o modelo de ensino que temos com esse modelo, mais voltado à formação do professor. Se numa turma houve uma adesão e não se questionou a metodologia, não significa necessariamente que a proposta foi bem aceita. Percebo que faltou de minha parte uma forma mais aberta para conduzir o processo, sobretudo na apresentação da proposta, quando poderia ter deixado os alunos mais à vontade para uma primeira avaliação do objetivo desse tipo de trabalho e aproveitado seus receios para apresentar já na disciplina de brasileira os documentos norteadores da educação básica. Deve-se ter claro que a maioria dos alunos não exerce a profissão de professor e tampouco teve acesso a essas diretrizes até metade do curso, o que torna um ensino sob essa concepção um tanto difícil.

É nesse sentido que há uma urgência em fazer com que o curso de Letras-Licenciatura se redesenhe a fim de que sejam demarcados seu perfil e sua identidade. O Projeto Político Pedagógico do curso aborda, entre outras, as seguintes competências:

a) o conhecimento das diferentes línguas e literaturas nas suas manifestações orais e escrita, assim como das teorias e dos métodos que 
fundamentam as investigações sobre a linguagem e a arte literária e facilitam a solução dos problemas nas diferentes áreas de saber;

b) análise e interpretação de obras literárias baseadas no domínio ativo de um repertório representativo de literatura;

c) conhecimento das relações de intertextualidade e reconhecimento das condições sob as quais a expressão linguística se torna literatura;

d) domínio de conceitos que possibilitem compreender e explicar a linguagem como uma faculdade inata e ao mesmo tempo um fenômeno cognitivo, sócio-histórico e cultural. ${ }^{12}$

De modo amplo e sem restrição, essas competências dão abertura para que se pensem metodologias nas quais o aluno seja levado a perceber a literatura como uma linguagem que não pode ser tomada autonomamente, porque sua própria concepção se volta para uma pluralidade de saberes, inclusive, o seu caráter de fronteira ao se relacionar com outras linguagens. Muito se tem discutido sobre a falta de tempo de leitura tanto na educação básica quanto no ensino superior. Também se discute que os alunos já não têm paciência para leituras extensas e não vão às obras literárias, mas à crítica sobre elas, porque o objetivo do estudo de literatura é teorizar, tornar um texto feito para provocação e formação um objeto de problema, a definição de um problema por um leitor especialista. Mas pouco se tem debatido sobre se a manutenção de um ensino positivista ainda teria sentido na contemporaneidade e como isso tem afetado a formação leitora tanto quanto a velha concepção que tomava o ensino de normatividade gramatical como fundamento para o ensino da língua materna sem levar em consideração todas as variações.

Como aborda a professora Eliana Kefalás, em Corpo a corpo com o texto na formação do leitor literário (2012), o olhar sobre o fenômeno literário é um desafio porque é necessário levar em consideração não apenas aspectos socioculturais e metodológicos, mas a própria experiência pessoal do leitor com o texto. Kefalás toma a leitura e a literatura como "lugar de desestruturação e formação do sujeito, como corporeidade, materialidade sensível, produtora de deslocamentos e estranhamentos" (2012, p. XXII). Antonio Candido, em "O direito à literatura", além de ampliar o domínio da literatura, incluindo aí o folclore, a lenda e até o chiste, situa-a como um valor de ordem "intelectual e afetiva" e instrumento poderoso a serviço da sociedade (2011, p. 177). Mas ele mesmo aponta que ela pode ser usada para combater ou apoiar um problema. Tzevetan Todorov, em A literatura em perigo, utilizando o programa oficial do ensino na França, questiona o caráter instrucional dos estudos literários, ou seja, "na escola, não aprendemos acerca do que falam as obras, mas sim do que falam os críticos" (2014, p. 27). Ao ser convidada para palestrar a respeito da importância dos parâmetros curriculares nacionais, a escritora e professora Ana Maria Machado assim encerra a discussão:

Eu acho que a diversidade e a integração são uma enorme força nossa, um dos nossos grandes tesouros para o século XXI. Estou convencida disso e é muito bom que a escola possa trabalhar bem essa nossa força. Mas, como disse, quando escrevemos, não pensamos em 'temas transversais' ou coisas similares. Isto se descobre é na leitura. A escrita não parte de intenções predeterminadas a esse respeito. Ela simplesmente acontece, e reflete como somos. Não uma série de ilhas distantes ou isoladas entre si. Mas um

\footnotetext{
${ }^{12}$ O PPP do curso de Letras da UFC foi elaborado em dezembro de 2005 e revisto em 2007.
} 


\section{Notandum 42 set-dez 2016 - CEMOrOC - Feusp / IJI-Univ. do Porto DOI: http://dx.doi.org/10.4025/notandum.42.2}

continente onde nem dá para saber direito onde um acaba e outro começa. (2004, p.133)

É em busca de uma corporeidade do texto literário que essas e outras atividades têm sido elaboradas. Se o curso de Letras seria por definição o lugar para se pensar por que é preciso ler literatura, por que ela nos move e nos comove ainda, por que o texto literário nos provoca para uma adesão a um modo de pensar o mundo livre das amarras do utilitarismo, cabe também a nós, professores e alunos, aceitar, no mínimo, que a estabilidade em nossas práticas de ensino seja abalada, porque a literatura talvez requer de nós não uma postura de defesa da sua história, mas do próprio texto.

Se citei experiências minhas e de meus alunos, também é preciso mencionar outras atividades que vêm sendo desenvolvidas há mais tempo no curso. Cito, por exemplo, as atividades permanentes do grupo "Verso de Boca", vinculado ao departamento de literatura (unidade de literatura portuguesa) e sob orientação da professora Elisabeth Gomes Martins, que tem se constituído como um corpo de difusão das literaturas e culturas lusófonas em eventos dentro e fora da instituição; a semana Entrepalavras, vinculada ao departamento de letras vernáculas, sob orientação da professora Claudete Lima, de caráter interdisciplinar no fomento à produção cultural no âmbito da UFC; e, mais recentemente, a criação do fanzine "A literação" por alunos de graduação que, diante do predomínio de estudos teóricos no curso, e na ânsia de divulgar suas próprias criações, articulam a produção e divulgação de textos, fotos e outras produções num estímulo ao exercício criativo, mas nem por isso menos crítico, do pensamento sobre o curso.

Não se trata de substituir métodos e formas de ensino, mas de possibilitar que os alunos, em suas diversas posturas e desejos, se identifiquem com uma vertente do curso e, assim, sigam sua formação com autonomia, construindo um percurso com ênfase em seus interesses e não no interesse singular da administração do curso, porque os meios de que dispomos para pensar a educação não podem limitar os fins, ou melhor, querer marcar o ensino com modelos ideais é incorrer no risco de se converter a organização do mundo numa espécie de ajustamento ideológico, como denunciava já no pós-guerra Theodor Adorno (1995) em suas reflexões a respeito de uma educação emancipadora. Ampliando essa reflexão, Paulo Freire também afirmava que "se há uma prática exemplar como negação da experiência formadora é a que dificulta ou inibe a curiosidade do educando e, em consequência, a do educador" (2011, p. 82). Que essas experiências aqui apresentadas sirvam para nos colocar em alerta a respeito das defesas do que achamos importante e, enfim, uma questão seja ruminada: o que queremos da literatura é o que a literatura quer de nós?

\section{REFERÊNCIAS}

ADORNO, T. Educação e emancipação. Rio de Janeiro: Paz e Terra, 1995.

BARTHES, R. O prazer do texto. São Paulo: Perspectiva, 1987.

CANDIDO, A. "O direito à literatura". In: Vários escritos. Rio de Janeiro: Ouro sobre azul, 2011.

CARNEIRO, M. A. O nó do Ensino Médio. Petrópolis, RJ: vozes, 2013. 
FREIRE, P. Pedadogia da autonomia: saberes necessários à prática educativa. São Paulo: Paz e Terra, 2011.

JOUVE, V. Por que estudar literatura? Tradução de Marcos Bagno e Marcos Marciolino. São Paulo: Parábola editorial, 2012.

KEFALÁS, E. Corpo a corpo com o texto na formação do leitor literário. Campinas; SP: Autores Associados, 2012.

MACHADO, A. M. Ilhas no tempo: algumas leituras. Rio de Janeiro: Nova Fronteira, 2004.

BRASIL, Ministério da Educação. Parâmetros Curriculares Nacionais: ensino médio. Brasília: Ministério da Educação, 1999.

BRASIL, Ministério da Educação. PCN+ Ensino Médio: orientações educacionais complementares aos Parâmetros Curriculares Nacionais. Linguagens, Códigos e suas Tecnologias. Brasília: MEC, SEMTEC, 2002.

BRASIL, Ministério da Educação. Diretrizes Curriculares Nacionais Gerais da Educação Básica. Secretaria de Educação Básica. Diretoria de Currículos e Educação Integral. Brasília: MEC, SEB, DICEI, 2013.

SANTOS, J. R. Quem ama literatura não estuda literatura. Rio de Janeiro: Rocco, 2008. TODOROV, T. A literatura em perigo. Tradução de Caio Meira. São Paulo: Difel, 2009. 